\title{
A Pastoral Necessity: Redefining Spirit Through the Body for the Healing and Flourishing of Trauma Survivors
}

\author{
Paige Cargioli \\ Boston College School of Theology and Ministry
}

Pastoral caregivers are mediators for healing both body and spirit. However, healing of the body through the spirit, and the spirit through the body is overlooked by caregiving disciplines. Different specialties emphasize more bodily healing or spiritual healing. For example, medical doctors and psychologists aim to heal bodies, while pastoral caregivers seek to heal the spirit. Additionally, this "healing" is complete once one reaches neutral functioning. I believe healing is, instead, a journey towards optimal functioning that is flourishing. In this paper, I explain how the body and spirit become disconnected in trauma survivors, and how those seeking healing ultimately are seeking to reconnect the body and spirit as one. That is to say, bodily trauma hurts the spirit, and vice versa. Secondly, I discuss the dangers of dualistic thinking and the language that separates body and spirit in society and among all types of caregivers, but especially pastoral caregivers. Finally, I connect how an integrative body/spirit approach leads to more holistic healing. Overall, I urge pastoral caregivers (as well as other disciplines) be more integrative, open-minded, and less dualistic in their approach to service and healing in order to build flourishing communities.

Paige Cargioli graduated from Pepperdine University with her Bachelors in Psychology, and at Boston College in May 2011 with her M.A. in Pastoral Care and Counseling from the School of Theology and Ministry as well as her M.A. in Mental Health Counseling from the Lynch School of Education. Her academic interests are in spirituality and the body, healing, trauma, forgiveness and reconciliation. 


\section{Introduction}

There is a grand lack in the Christian pastoral literature relating to the body and healing, and this is a problem. It is a problem because pastoral caregivers claim (or are dubbed) healers of the soul, calmers of the spirit, or peacemakers - and all of these roles include the body at some point in the healing process. Usually, the cause of a "hurt spirit" is due to a bodily affliction of one individual or another. How a pastoral minister incorporates the body is difficult to address since care for the body is typically assigned to the realm of psychologists and medical doctors. However, even medical doctors and psychologists understand the importance of reconnection of body and spirit, and even more so, it is the job of the pastoral caregiver to learn how this reconnection can be facilitated. In this paper, I will first discuss the body/spirit disconnect that is apparent in trauma survivors. Secondly, there will be a discussion on the difficulty of language and the dualistic thinking that permeates society (even when one attempts not to be dualistic). And finally, I will relate these issues back to bodily trauma (violence and abuse) and healing (through community, verbally, and non-verbally).

People disconnect from their bodies in severe trauma or pain, and trauma theorists call this dissociation. For example, one who has experienced sexual abuse may not experience any compassionate intimacy or pleasure in sexual experience. On the other hand, some who experience trauma react with hyperarousal. So, depending on the stimuli, those who have experienced trauma may demonstrate both types of the above coping. ${ }^{1}$ For instance, in the same case of sexual abuse above, one may exhibit exaggerated stimulation by a simple touch or

\footnotetext{
${ }^{1}$ Several sources discuss this such as: C. Hess, "Traumatic Violence and Christian Peacemaking", Brethren Life and Thought, 51 (2006): 201-220; C. Hess Sites of Violence, Sites of Grace (Lanham, MD: Lexington Books, 2009); R. Mollica, Healing Invisible Wounds (Orlando, FL: Harcourt, Inc, 2006); B. Rothschild, The Body Remembers (New York, NY: W.W. Norton \& Company, 2002); S.R. Tracy, Mending the Soul: Understanding and Healing Abuse (Grand Rapids, MI: Zondervan, 2005); A.J. Weaver, L.T. Flannelly, and J.D. Preston, Counseling Survivors of Traumatic Events: A Handbook for Pastors and Other Helping Professionals (Nashville, TN: Abingdon Press, 2003).
} 
gesture (e.g. jump in surprise). Besides sexual abuse, there are a number of ways that a person might disconnect from their body: past experiences of being shamed, society, culture, pain, illness, oppression, suffering, and any form of violence. Consequently, humans do things to foster a reconnection to their body (e.g. exercise, yoga, meditation, massage, prayer, sex, eat) or enhance the disconnection from their body (e.g. drugs, alcohol, virtual reality, excessive sleep). I am suggesting here that the cognitive and behavioral reconnection of mind/psyche/spirit/soul and the physical body allows for healing and flourishing of mind/psyche/spirit/soul and the physical body.

There are many words that are ill-defined in referring to the intangible human experience of mind, psyche, spirit, or soul, and I group these words together because there is an overlap in the general understanding and use of these words. Some words are more religiously charged, such as spirit and soul, and some might be more psychologically charged such as mind, psyche, and cognition. All of these words, however, often refer to a similar amorphous expression. Another word rarely claimed by religious people (specifically Christian) or psychologically minded people is the new age (or spiritual, but not religious) understanding of "energy." Again, this refers to the same thing: some arduously expressed feeling, thing, or presence, that a person may or may not acknowledge within (and outside) of themselves and others. For example, if someone says that his or her soul is tired, what does that mean? Does it mean that their body is tired as well, or is the body simply disregarded? What causes one to say such a thing, and what changes this state?

While counselors, pastoral ministers, and psychologists attempt to operationally define the differences in the understandings and experiences of these words, defining and understanding the physical body and healing (often in relationship to these words) is neglected. In light of this 
overlap of definitions and the theological nature of this paper, I will use the words "spirit" or "soul" in reference to all of these abstract expressions.

Another reason I group these words together is also in attempt to save the reader from the endless attempt of teasing out the differences of these words. Instead of arguing the differences, I see the similarities of these words and their capacity to be holistically used for healing. That is, understanding that each person a caregiver works with is different, and it is the caregiver's job to understand how another person understands and interprets "spirit" (with whatever words they chose). The work of healing that pastoral caregivers seek is not dependent on understanding the words systematically (while it may be helpful for the caregiver's own journey), but how another uses and interprets them in the context of their own life and journey towards healing - healing both body and spirit. Consequently, dualism comes into play as people separate body and spirit in their language. Dualism, as it is understood in this paper, is the state of two things being divided and defined separately, but in light of the other. How is it that something be divided if it is irrevocably connected by the opposing definition of the other? To define spirit, body must be used, and to define body, spirit must be used.

So, the dualistic understanding that I refer to is the idea that healing of the body is not dependent on healing of the spirit, and healing of the spirit is not dependent on the body. Consequently, understanding the intimate connection of spirit and body is the first step to healing and flourishing in the body and spirit (connected). Flourishing is a concept in positive psychology defined by Gable and Haidt as the "optimal functioning of people, groups, and institutions." 2 The difference, then, between healing and flourishing is that healing often has to do with handling a process from the past that is likely exhibiting itself in the present, and

\footnotetext{
${ }^{2}$ S.L. Gable and J. Haidt, "What (and Why) is Positive Psychology?" Review of General Psychology 9, no. 2 (2005): 103 .
} 
flourishing has to do with continued "optimal functioning" into the future. Psychologists have begun to understand how the spirit and body are connected in the healing process for future flourishing. So, psychologists and counselors integrate in their work spirit and body to heal spirit and body for the past, present, and future. For example cognitions are like the spirit, and behavior has to do with the body. When someone says, "My spirit is tired," what they mean is that their spirit feels tired. This awareness and expression is the cognitive or spiritual dimension and the actual, tangible, bodily feeling that comes about is the behavioral or physical aspect. It is important then, for the sake of reconnection of the body and the spirit, to ask questions to lead to more detailed expression and feeling. Gendlin developed a technique called "Focusing" to help people connect to the bodily experiences of their inexpressible feelings often associated with the spirit. $^{3}$

Despite this, much of Christian literature focuses on the "soul" and this is demonstrated simply through book titles like Tracy's Mending the Soul. ${ }^{4}$ The reason for this focus might be because the physical body is claimed by medical doctors, and the mind and cognitions are claimed by psychologists. Consequently, spiritual and religious people claim the soul or spirit. Yet, in fact, how exclusive is the body from the mind, spirit or soul? I argue not at all, especially in defining healing. It is important for ministers and pastoral counselors to remember that the body cannot be excluded from the spirit, and vise versa. Violence and abuse afflicted upon the body afflicts the soul, and likewise, it is care and love for the estranged body that can heal the soul and allow for flourishing. Strathern and Stewart emphasize a particular difference in curing and healing,

Curing, narrowly conceived, may be said to separate mind and body, whereas healing can be said to unite them [...] Typically, if a condition is seen as minor

\footnotetext{
${ }^{3}$ E.T. Gendlin, Focusing (New York, NY: Bantam Books, 1972).

${ }^{4}$ Tracy, Mending the Soul: Understanding and Healing Abuse (Grand Rapids, Michigan: Zondervan, 2005).
} 
and yields easily to a remedy or goes away by itself, it is subject to curing; if it is harder to deal with, a wider set of therapies may be engaged in, entailing a deeper search for causes in the interpersonal and social realm of relationships. 5

Here, it is understood that healing is more holistic and possibly more difficult than curing.

Curing is specifically biological, while healing is more all-encompassing (past, present, future, spirit, and body). Hence, to return to an earlier example, a tired soul cannot be simply be cured, it must be healed.

Like I have already said, religious healing is often specific to healing the soul or spirit, but according to Strathern and Stewart's distinction healing goes beyond the spirit and encompasses both body and spirit united. Unfortunately, it is incredibly difficult to find reliable holistic healing sources and mending of the spirit and body in Christian literature. For instance, Hardesty writes in her book about the faith healing movements of the Pentecostal church, a movement and population that has been neglected by psychologists as well as mainstream Christianity. This population has probably been neglected in research because there is so much variation across Pentecostal groups and their healing practices are mystical and mysterious. Nevertheless, such movements utilize healing of the body (e.g. miracles often attributed to prayer in the Holy Spirit) to evangelize and convert, i.e. saving the soul. ${ }^{6}$ What is being sought after in this paper is a healthy integration and awareness of body language in order for natural healing to take place. Even in the small amount of literature seeking a healthy, non-exclusive appeal to body and soul (like this paper) still display moments of dualistic thinking. Even so, it is my goal to emphasize that the body, mind, and spirit are intimately intertwined and one cannot be spoken about without influence on the other.

\footnotetext{
5 A. Strathern and P.J. Stewart, "Embodiment Theory in Performance and Performativity," Journal of Ritual Studies, 22, no. 1 (2008): 67.

${ }^{6}$ N.A. Hardesty, Faith Cure: Divine Healing in the Holiness and Pentecostal Movements. Peabody, MA: Hendrickson Publishers, 2003.
} 
As has been demonstrated, it is incredibly difficult to strictly define the words spirit, mind, and psyche, and the physical body is simply understood as the biological body. But again, what makes the difference? Why such a dualistic understanding in the realm of Christianity? Well, the fact is that the dualism exists, and comprehension needs to change-especially in our spirit-focused world where bodily trauma is often ignored. Fortunately, there are nuggets of this understanding in some current Christian literature on trauma, healing, pastoral care, psychology, and medicine that may lead to a more fully developed awareness of spirit/body healing integration.

Ramsay discusses in her article the delicate process of confronting family violence and the spiritual devastation that it brings. While, again, her article appears to be giving specific attention to the spirit, Ramsay makes a point of including how the body can be negatively affected, and that there is a need to appreciate the body for healing. Bodily tragedy leads to bodily manifestations of the issue, and it is important for pastoral people to remember and address this (such as in the manner of "focusing" prescribed by Gendlin). ${ }^{7}$ In addition to the violent acts themselves, there are bodily consequences that are listed by Ramsay (citing Russell) including "distortions in self-esteem, anxiety, eating disorders, distortions of body image, sexual dysfunction, disrupted relationships, dysfunction in school and work, and increased risk of suicide." ${ }^{8}$ With all this on the table, Ramsay makes note of how the human being is made in the image of God. Further, she states,

Closely related is the affirmation that we are created as embodied persons whose embodiment deserves tender care that always respects the integrity and inviolability of each person. God's choice to dwell with us as a human being further emphasizes that bodies matter to God, and they need to matter to us. God's

\footnotetext{
${ }^{7}$ Gendlin, Focusing.

${ }^{8}$ D. Russell, The Secret of Trauma: Incest in the Lives of Girls and Women (New York: Basic Books, 1986) cited in N.J. Ramsay’s, “Confronting Family Violence and Its Spiritual Damage," Journal of Family Ministry, 20, 3 (2006): 30 .
} 
incarnation in Jesus highlights the centrality of embodiment in Christian tradition and rejects any dualism that would deny or trivialize the inextricable relation of embodiment and human experience. We bear witness to God's image in us and others through our practices of love for one another that is life enhancing, healing, and encouraging. ${ }^{9}$

Ramsay continues to explain that "Tragically, the locus of embodiment God intends precisely for our most profound experiences of intimate communion becomes a source of isolating shame and fear spiritually and relationally for many survivors of child sexual abuse. ${ }^{10}$ While she highlights the importance of embodied persons, she does not discuss how to address this specifically. In the end, Ramsay's article comes down to the importance of God's love and justice, self-love, forgiveness and reconciliation. How this is exemplified is through the community, or as Hess characterizes it: the body.

Hess in her writing explains some of the background of trauma, specifically posttraumatic stress disorder (PTSD), and how Christians ought to approach trauma with healing in mind. Accordingly, "Traumatic events call into question basic human relationships. They breach attachments of family, friendship, love, and community. They shatter the construction of the self that is formed and sustained in relation to others." ${ }^{\prime 1}$ The fragmentation of relationships also takes place in relationship with God, as well as relationship to self. She then gives what trauma theorists believe brings about healing in trauma survivors as well as a theological perspective on trauma. For trauma theorists, the first thing that allows for healing is a supportive community, that is, the body. This is heavily emphasized in religious as well as psychological literature. ${ }^{12}$ A second requirement, explicated by Hess, is that that the inexpressible traumatized

\footnotetext{
9 Ramsay, “Confronting Family Violence," 30.

${ }^{10}$ Ibid., 31.

${ }^{11}$ Judith Lewis Herman cited by Hess, “Traumatic Violence and Christian Peacemaking," Brethren Life and Thought, 51 (2006): 207.

${ }^{12}$ Emphasized by Hess, "Traumatic Violence and Christian Peacemaking," and Sites of Violence; Mollica, Healing Invisible Wounds; Ramsay, "Confronting Family Violence"; Tracy, Mending the Soul.
} 
event needs to be integrated into the larger context of the survivor's story verbally. The community, or body, needs to acknowledge trauma with the survivor in whatever capacity that is most important for the survivor. Mollica, in his interviews with Cambodian and Bosnian refugees, found that narrative is an incredibly healing avenue for trauma survivors, those of which who, before, were misunderstood in their cultural context. ${ }^{13}$ The last step, listed by Hess in order for trauma survivors to completely heal, is retemporalization. Beyond the verbal integration of the trauma story, it is important for the survivor to reorient his or her self to the present no longer retraumatized by the event, i.e. "the creation of a context in which traumatized people can survive and flourish." ${ }^{\prime 14}$ This retemporalization, or reorientation, is a holistic transformation where the survivor reconnects to their body (individual and communal), that is, the site of trauma, but now can be re-viewed as a site of healing for both the individual body and the communal body.

Hess then takes on the theological perspective of healing and trauma in the works of John Howard Yoder. In reference to the larger narrative of Jesus, she states, “This emphasis on performance and embodiment resonates with a point trauma theorists often make: healing involves the body. In Christian community, healing involves both the individual and the social body." 15 Indeed, healing includes a multitude of bodies working for healing. Hess suggests this is through nonviolence, which "must "entail not only action for social change in relation to the external, physical violence but also the transformation of internal, traumatic violence." 16 Here, the external is the physical body or bodies, and the internal is the spiritual. Overall, Hess' work

\footnotetext{
${ }^{13}$ Mollica, Healing Invisible Wounds, 110-133.

${ }^{14}$ Hess, "Traumatic Violence and Christian Peacemaking," 214.

${ }^{15}$ Patricia Weaver Francisco, Telling: A Memoir of Rape and Recovery (New York: Cliff Street Books, 1999), 14451 cited in Hess, "Traumatic Violence and Christian Peacemaking," 210.

${ }^{16}$ Hess, "Traumatic Violence and Christian Peacemaking, 215.
} 
is indicative of a larger incorporation and integration of healing by the church body for the individual body.

Much of what is suggestive for healing in the literature thus far is verbal. ${ }^{17}$ For some, however, verbal expression of traumatizing events is incredibly difficult, if not impossible. Hess explains, "Many trauma theorists believe that since trauma is stored in the body, physical experiences can unlock dissociated memories and help survivors confront hidden dimensions of their traumas."18 Following is an example of a non-verbal process of healing through dance (as opposed to the "talking cures") for survivors of childhood sexual abuse. ${ }^{19}$

Mills and Daniluk's qualitative study followed five women's experience of dance therapy in healing their trauma of childhood sexual abuse. The participants had to complete six sessions of dance therapy within one year's time. All of the survivors recruited were specifically seeking healing for their trauma. Once the sessions were completed, each participant did a qualitative research interview in order to assess each individual's process of healing. Accordingly, there were six themes that arose from the interviews, three of which are incredibly bodily. Firstly, the women experienced extreme liberation from businesslike arenas that often therapy is associated. This liberation was a "permission to play." The women were very much encouraged to play, and this encouragement meant the freedom to feel, explore, and learn "that play and work could coexist.",20

The next themes explicated from the study go hand in hand, that is "reconnection to their bodies" 21 and a "sense of intimate connection." 22 These work together because the women in the

\footnotetext{
${ }^{17}$ Such as Hess, "Traumatic Violence and Christian Peacemaking," and Sites of Violence; Mollica, Healing Invisible Wounds; Ramsay, "Confronting Family Violence"; Tracy, Mending the Soul.

${ }^{18}$ C. Hess, Sites of Violence, Sites of Grace, (Lanham, MD: Lexington Books, 2009), 74.

${ }^{19}$ L.J. Mills and J.C. Daniluk, "Her Body Speaks: The Experience of Dance Therapy for Women Survivors of Child Sexual Abuse," Journal of Counseling and Development, 80 (2002): 77-85.

${ }^{20}$ Ibid., 80 .

${ }^{21}$ Ibid., 79
} 
group recognized the reconnection they had with themselves as well as the deeper connection cultivated between group members. In addition, the women actually sought dance therapy (as opposed to "talk therapies") as a means to connect to their bodies. One of the participants recounted their original feelings towards their body, "I thought of my body as this unfortunate accessory... it has just caused me trouble... it always felt like the enemy."23 Afterwards, however, another participant explained, "you get total awareness of your body... it was exciting... even talking about it now I get tingly... it felt like coming alive."24 This therapy ultimately made them "able to reunite their minds and bodies, to reconnect to split-off parts of the self, and to recover and reclaim their emotional and psychological worlds." 25 The women expressed a sense of ownership of their bodies and the experience within. Next, the "sense of intimate connection" ${ }^{26}$ was one that they felt for each other in the process of dance therapy, words not necessary. Similarly, to their own bodily connection, the women gained the awareness of the interpersonal unity in the dance as well as the physical and emotional acceptance and support given and received. Mills and Daniluk's research is just one example of how important it is to address the body for those who have experienced trauma.

In this paper, I have explained how trauma survivors are physically and spiritually impacted by trauma, how the way in which one defines spirit and body (together and separate) may further or hinder healing for future flourishing (i.e. healthy reconnection of spirit and body), and lastly, I argue for the integration of communal and non-verbal approaches in pastoral caregiving. For some, their trauma is large, while for others the trauma might be small, but to some extent, everyone experiences spirit-body disconnect and often longs for the healing of

\footnotetext{
${ }^{22}$ Ibid., 81

${ }^{23}$ Ibid., 79.

${ }^{24}$ Ibid., 80.

${ }^{25}$ Ibid.

${ }^{26}$ Ibid., 81 .
} 
reconnection. The difficulty is raising awareness and finding a proper modality, action, words, or community for trauma survivors' healing and flourishing. Separation of spirit and body or the understanding of spirit as greater than body has permeated much of human thought, yet the reconnection is continually sought after (or avidly avoided). It is important for counselors, doctors, ministers, or any caregiver to realize the importance of bodily awareness and interaction for the sake for holistic healing and continued flourishing of all people. 